\title{
Novel substituted 1,4-anthracenediones with antitumor activity directly induce permeability transition in isolated mitochondria
}

\author{
ELISABETH M. PERCHELLET ${ }^{1}$, YANG WANG ${ }^{1}$, KAIYAN LOU ${ }^{2}$, HUIPING ZHAO $^{2}$, \\ SRINIVAS K. BATTINA ${ }^{2}$, DUY H. HUA ${ }^{2}$ and JEAN-PIERRE H. PERCHELLET ${ }^{1}$ \\ ${ }^{1}$ Anti-Cancer Drug Laboratory, Division of Biology, Ackert Hall; \\ ${ }^{2}$ Department of Chemistry, Kansas State University, Manhattan, KS 66506-4901, USA
}

Received May 8, 2007; Accepted July 6, 2007

\begin{abstract}
Synthetic analogs of 1,4-anthraquinone (AQ code number), which block nucleoside transport, decrease DNA, RNA and protein syntheses, trigger cytochrome $c$ release without caspase activation, induce apoptotic DNA fragmentation and inhibit the proliferation of wild-type and multidrug resistant tumor cells in the $\mathrm{nM}$ range in vitro, rapidly cause the collapse of mitochondrial transmembrane potential in cell and cell-free systems. Because mitochondrial permeability transition (MPT) requires more than depolarization to occur, antitumor AQs were tested for their ability to directly trigger specific markers of MPT in isolated mitochondria. In contrast to a spectrum of conventional anticancer drugs that are inactive, various $\mathrm{AQs}$ interact with isolated mitochondria in a concentration- and time-dependent manner to rapidly cause large amplitude swelling and $\mathrm{Ca}^{2+}$ release in relation with their effectiveness against L1210, HL-60 and LL/2 tumor cells in vitro. Indeed, the lead antitumor AQ8, AQ9 and AQ17 are also the most effective inducers of MPT in isolated mitochondria, whereas all AQ derivatives devoid of antiproliferative activity also fail to trigger mitochondrial swelling and $\mathrm{Ca}^{2+}$ release. Moreover, the ability of $4 \mu \mathrm{M} \mathrm{AQ17}$ to maximally induce mitochondrial swelling and $\mathrm{Ca}^{2+}$ release within $15 \mathrm{~min}$ is similar to that of classic MPT-inducing agents, such as $5 \mu \mathrm{g} / \mathrm{ml}$ alamethicin, $200 \mu \mathrm{M}$ atractyloside, $5 \mu \mathrm{M}$ phenylarsine oxide, $100 \mu \mathrm{M}$ arsenic trioxide and a $100 \mu \mathrm{M} \mathrm{Ca}^{2+}$ overload. Interestingly, AQ17 requires a priming concentration of $20 \mu \mathrm{M} \mathrm{Ca}^{2+}$ to trigger mitochondrial swelling and $\mathrm{Ca}^{2+}$ release and these $0.1 \mu \mathrm{M}$ ruthenium red-sensitive MPT events are abolished by $1 \mu \mathrm{M}$ cyclosporin A, $2 \mathrm{mM}$ $\mathrm{ADP}$ and $20 \mu \mathrm{M}$ bongkrekic acid, which block components
\end{abstract}

Correspondence to: Professor J.-P. Perchellet, Anti-Cancer Drug Laboratory, Kansas State University, Division of Biology, Ackert Hall, Manhattan, KS 66506-4901, USA

E-mail: jpperch@ksu.edu

Key words: antitumor 1,4-anthracenediones, tumor cell proliferation, isolated mitochondria, mitochondrial swelling, mitochondrial $\mathrm{Ca}^{2+}$ release of the permeability transition pore (PTP), and also inhibited by $50-100 \mu \mathrm{M}$ of various ubiquinones, which interact with the quinone binding site of the PTP and raise the $\mathrm{Ca}^{2+}$ load required for PTP opening. Hence, antitumor AQs that target isolated mitochondria and trigger MPT might directly interact with components of the PTP to induce conformational changes that increase its $\mathrm{Ca}^{2+}$ sensitivity and transition from the closed to the open state.

\section{Introduction}

In contrast to their inactive precursor quinizarin (AQ2, 1,4dihydroxy-9,10-anthraquinone), synthetic analogs (AQ code number) of 1,4-anthraquinone (AQ1, anthracene-1,4-dione) inhibit L1210 and wild-type, drug-sensitive, HL-60 tumor cell proliferation within 2-4 days, and DNA, RNA and protein syntheses within 2-3 h (1-4). They reduce the mitotic index within $24 \mathrm{~h}$, suggesting that they arrest early stages of cell cycle progression. New RNA and protein syntheses, and the activation of endonucleases are required to sustain the active mechanism by which low concentrations of AQs induce as much apoptotic DNA fragmentation at $24 \mathrm{~h}$ as 20 (S)-camptothecin and daunorubicin (DAU, daunomycin) $(1,2)$. One advantage over DAU is that AQs totally block the cellular uptake of both purine and pyrimidine nucleosides within 15 min $(1,2)$, an antitumor effect that might potentiate the action of antimetabolites. Because these antitumor effects persist upon drug removal, AQs may rapidly and irreversibly interact with various molecular targets in cell membranes and nuclei. Moreover, AQs retain their efficacy in multidrugresistant (MDR) HL-60-RV and HL-60-R8 sublines that have different mechanisms of resistance to DAU. Taken together, these findings suggest that these novel synthetic AQ1 analogs might have a wider spectrum of molecular targets than DAU, and might be valuable in polychemotherapy to circumvent mechanisms of MDR (2).

Based on their ability to decrease by $50 \%$ the metabolic activity of L1210 and HL-60 cells at day 4 ( $\mathrm{IC}_{50}$ values) in the $\mathrm{nM}$ range, using the 3-(4,5-dimethylthiazol-2-yl)-5-(3carboxymethoxyphenyl)-2-(4-sulfophenyl)-2H-tetrazolium (MTS):phenazine methosulfate (PMS) (2:0.1) assay reagent to assess mitochondrial metabolism, 6-methyl-1,4-anthracenedione (AQ8), 6-bromomethyl-1,4-anthracenedione (AQ9) 


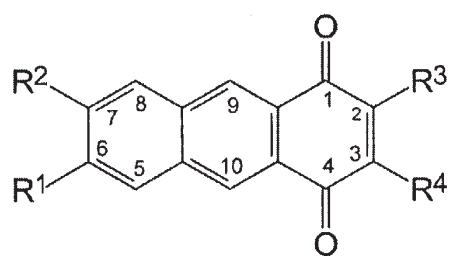

AQ8, AQ9, AQ14-AQ17

\begin{tabular}{|c|c|c|c|c|c|}
\hline \multicolumn{3}{|c|}{ Compounds } & \multicolumn{3}{|c|}{$I C_{50}$ values $(\mathrm{nM})^{a}$} \\
\hline Code & Residues & & L1210 & HL-60 & $\mathrm{LL} / 2$ \\
\hline No. & $\mathrm{R}^{1}$ & $R^{2} R^{3} R^{4}$ & cells & cells & cells \\
\hline AQ8 & $\mathrm{CH}_{3}$ & $\mathrm{H} \mathrm{H} \mathrm{H}$ & $29 \pm 1$ & $87 \pm 4$ & $760 \pm 52$ \\
\hline AQ9 & $\mathrm{CH}_{2} \mathrm{Br}$ & $\mathrm{H} \mathrm{H} \mathrm{H}$ & $26 \pm 1$ & $79 \pm 3$ & $680 \pm 87$ \\
\hline AQ14 & $\mathrm{CH}_{2}$-(1,3,4,6-tetra-O-acetyl- $\beta$-D-glucosamino) & $\mathrm{H} \mathrm{H} \mathrm{H}$ & $196 \pm 18$ & $254 \pm 23$ & $813 \pm 74$ \\
\hline AQ15 & A hydrogen chloride salt of AQ14 & $\mathrm{HH} H$ & --- & $1,980 \pm 76$ & --- \\
\hline AQ16 & $\mathrm{CH}_{2}-[(-)$-quinic acid ester $]$ & $\mathrm{H} \mathrm{H} \mathrm{H}$ & $524 \pm 34$ & $919 \pm 78$ & -- \\
\hline AQ17 & [di(t-butyloxy)phosphonyloxy]methyl & $\mathrm{H} \mathrm{H} \mathrm{H}$ & $23 \pm 2^{\mathrm{b}}$ & $133 \pm 9^{c}$ & $654 \pm 48^{b}$ \\
\hline
\end{tabular}

Figure 1. Concentrations of AQs required to inhibit by $50 \%$ ( $\mathrm{IC}_{50}$ values) the metabolic activity of L1210, HL-60 and LL/2 tumor cells, using the MTS:PMS assay at day 4 in vitro. ${ }^{\mathrm{a} M e a n s} \pm \mathrm{SD}(\mathrm{n}=3)$; ${ }^{\mathrm{b}}$ not different from $\mathrm{AQ} 9 ;{ }^{\mathrm{c}} \mathrm{P}<0.005$, greater than $\mathrm{AQ} 9$.

and 6-hydroxymethyl-1,4-anthracenedione (AQ10), which have more antiproliferative activity than AQ1, are our current lead antitumor compounds $(3,4)$. Since AQ2 with its internal quinoid B-ring is devoid of antitumor activity, it is reasonable to assume that the external para-quinone is responsible for the potent antitumor activity of the AQ1 framework. Structureactivity relationships indicate that the bioactivity of AQ1 analogs is hindered by the presence of a substituent on their external quinone A-ring, whereas the functionalization of the C6-methyl group on the C-ring of AQ8 may enhance the antitumor activity (5). Compounds AQ1 and AQ8-10 also inhibit irreversibly the proliferation of Lewis lung carcinoma (LL/2) cells in vitro, suggesting that the classic LL/2 tumor model would be appropriate to assess the effectiveness of these drugs against solid primary tumor growth and metastasis in mice in vivo (5). The potent antitumor effects of AQ8-10 in vitro are all the more remarkable that, among synthetic or naturally occurring quinones, the number of bioactive 1,2-, 1,4and 9,10-AQs appears quite limited, very few elicit antitumor effects in vivo and, with the exception of mitoxantrone, none of them seems to match the potency of our lead AQs in vitro (1-5). The antiproliferative and cytotoxic activities of AQ9 (NSC 727286) have been confirmed in all 60 human tumor cell lines of the NCI's in vitro antitumor screen. Although this drug is somewhat more potent against ascitic than solid tumors, the selectivity pattern indicates that a wide spectrum of human tumor cells are sensitive to AQ9 inhibition (5). As an attempt to improve their antitumor activity, novel C-6 substituted AQ structures have been synthesized and tested in the present study.

Compounds AQ8-10 trigger several early and late markers of apoptosis in wild-type and MDR HL-60 cells, including cytochrome $c$ (Cyt $c$ ) release, caspase-2, -8, -9 and -3 activation and poly(ADP-ribose) polymerase- 1 cleavage within $6 \mathrm{~h}$ and internucleosomal DNA fragmentation within $24 \mathrm{~h}$ (3). AQ8 and
AQ9 induce a caspase-independent release of mitochondrial Cyt $c$ and a caspase-2-mediated activation of initiator caspase- 8 and -9 and effector caspase- 3 in HL-60 cells by a mechanism which does not involve Fas signaling since it is insensitive to antagonistic anti-Fas and anti-FasL monoclonal antibodies (3). Also the caspase-8 inhibitor benzyloxycarbonyl (z)-Ile-GluThr-Asp (IETD)-fluoromethyl ketone (fmk) does not prevent AQ8-induced Cyt $c$ release and caspase-2, -9 and -3 activation, but the caspase-2 inhibitor z-Val-Asp-Val-Ala-Asp (VDVAD)fmk totally blocks AQ8-induced caspase-9, -3 and -8 activities without altering AQ8-induced Cyt $c$ release. Antitumor AQ treatments, therefore, can fully release mitochondrial Cyt $c$ without caspase activation but AQ-induced caspase-2 activity may be an apical event required for the activation of a downstream cascade of other initiator and effector caspases (3). Fluorescent probes that are specific of mitochondrial transmembrane potential $(\Delta \Psi \mathrm{m})$ were used to demonstrate that antitumor AQ analogs, which can trigger Cyt $c$ release without caspase activation and retain their ability to induce apoptosis in DAU-resistant HL-60 cells, might have the advantage of directly targeting mitochondria in cell and cellfree systems to cause the collapse of $\Delta \Psi \mathrm{m}(\downarrow \Delta \Psi \mathrm{m})$ that is linked to permeability transition pore (PTP) opening (6).

Using JC-1 dye, the abilities of various AQs to induce the $\downarrow \Delta \Psi \mathrm{m}$ in wild-type and MDR HL-60 cells are rapid, within 2.5-10 min, irreversible after drug removal, concentrationdependent in the $0.256-10 \mu \mathrm{M}$ range, and related to their antitumor activities in vitro but not prevented by caspase- 2 or -8 inhibitor pretreatments, suggesting that activations of these apical caspases upstream of mitochondria are not involved in this process (6). Antitumor AQs also mimic the abilities of the known depolarizing agents, carbonyl cyanide $m$-chlorophenylhydrazone (CCCP), alamethicin, gramicidin A and $100 \mu \mathrm{M} \mathrm{CaCl}_{2}$, to directly induce, within $15 \mathrm{~min}$, the $\downarrow \Delta \Psi \mathrm{m}$ in isolated mitochondria prepared from mouse liver 
Table I. Comparison of the direct MPT-inducing activities of various antiproliferative AQs in isolated mitochondria.

\begin{tabular}{|c|c|c|}
\hline \multirow[t]{2}{*}{ Treatment $^{\mathrm{a}}$} & \multicolumn{2}{|c|}{ Markers of MPT } \\
\hline & $\begin{array}{l}\text { Mitochondrial swelling } \\
\text { Absorbance at } 540 \mathrm{~nm}^{\mathrm{b}}\end{array}$ & $\begin{array}{c}\text { Mitochondrial } \mathrm{Ca}^{2+} \text { release } \\
\text { Fluo-5N fluorescence } \\
\text { intensity (a.u. })^{\mathrm{b}}\end{array}$ \\
\hline Control & $0.346 \pm 0.017$ & $36.6 \pm 2.3$ \\
\hline $100 \mu \mathrm{M} \mathrm{Ca}^{2+}$ & $0.202 \pm 0.007$ & $605.4 \pm 35.1$ \\
\hline $20 \mu \mathrm{M} \mathrm{Ca}^{2+}$ & $0.334 \pm 0.021^{\mathrm{c}}$ & $41.3 \pm 3.3^{c}$ \\
\hline + AQ1 & $0.230 \pm 0.009$ & $137.3 \pm 8.8$ \\
\hline$+\mathrm{AQ} 2$ & $0.324 \pm 0.013^{\mathrm{d}}$ & - \\
\hline$+\mathrm{AQ} 3$ & $0.328 \pm 0.012^{\mathrm{d}}$ & - \\
\hline + AQ4 & $0.242 \pm 0.016$ & $117.1 \pm 6.9$ \\
\hline + AQ5 & $0.330 \pm 0.017^{\mathrm{d}}$ & - \\
\hline + AQ6 & $0.326 \pm 0.014^{\mathrm{d}}$ & - \\
\hline + AQ7 & $0.331 \pm 0.015^{\mathrm{d}}$ & - \\
\hline + AQ8 & $0.221 \pm 0.008$ & $150.1 \pm 8.1$ \\
\hline + AQ9 & $0.212 \pm 0.008$ & $152.6 \pm 11.0$ \\
\hline + AQ10 & $0.224 \pm 0.007$ & $144.9 \pm 10.1$ \\
\hline + AQ11 & $0.265 \pm 0.016^{\mathrm{e}}$ & $87.1 \pm 7.6^{\mathrm{f}}$ \\
\hline + AQ12 & $0.232 \pm 0.012$ & $113.5 \pm 7.3$ \\
\hline + AQ13 & $0.326 \pm 0.012^{\mathrm{d}}$ & - \\
\hline + AQ14 & $0.242 \pm 0.014$ & $111.6 \pm 8.9$ \\
\hline + AQ16 & $0.255 \pm 0.013$ & $93.3 \pm 6.4$ \\
\hline + AQ17 & $0.194 \pm 0.008^{g}$ & $176.5 \pm 9.9^{\mathrm{g}}$ \\
\hline
\end{tabular}

${ }^{a}$ Isolated mitochondria were incubated for $15 \mathrm{~min}$ with $4-\mu \mathrm{M}$ concentrations of AQs in the presence of a $20 \mu \mathrm{M} \mathrm{Ca}^{2+}$ primer; ${ }^{\mathrm{b}}$ means $\pm \mathrm{SD}(\mathrm{n}=3)$; ${ }^{\mathrm{c}}$ not different from control; ${ }^{\mathrm{d}}$ not different from $20 \mu \mathrm{M} \mathrm{Ca}^{2+}$; ${ }^{\mathrm{e}} \mathrm{P}<0.025$ and ${ }^{\mathrm{f}} \mathrm{P}<0.005$, respectively smaller and greater than $20 \mu \mathrm{M} \mathrm{Ca}^{2+}$; ${ }^{\mathrm{g}} \mathrm{P}<0.05$, smaller or greater than respective AQ9 values. a.u., arbitrary units.

and loaded with rhodamine 123 (Rh 123) dye (6). The fact that $20 \mu \mathrm{M} \mathrm{Ca}^{2+}$, which is insufficient to trigger depolarization on its own, is required to prime the depolarizing effect of AQ9 in isolated mitochondria suggests that antitumor AQs might interact with the PTP to alter its conformation and increase its $\mathrm{Ca}^{2+}$ sensitivity. Indeed, such $\mathrm{Ca}^{2+}$-dependent $\downarrow \Delta \Psi \mathrm{m}$ in isolated mitochondria treated with $1.6 \mu \mathrm{M}$ AQ9 or $100 \mu \mathrm{M} \mathrm{Ca}^{2+}$ is blocked by ruthenium red (RR), which prevents the $\mathrm{Ca}^{2+}$ uniporter from accumulating the exogenously added divalent cation into the mitochondrial matrix (6). DAU is unable to mimic the rapid $\downarrow \Delta \Psi \mathrm{m}$ caused by antitumor AQs within 2.5-40 min of treatment in HL-60 cells or isolated mitochondria. Moreover, the $\downarrow \Delta \Psi \mathrm{m}$ caused by $1.6 \mu \mathrm{M}$ AQ9 or $100 \mu \mathrm{M} \mathrm{Ca}^{2+}$ in isolated mitochondria is similarly blocked by cyclosporin A (CsA), bongkrekic acid (BA) and decylubiquinone (d-Ub), which prevent PTP opening, suggesting that, in contrast to DAU, antitumor AQs that directly target mitochondria to trigger the $\mathrm{Ca}^{2+}$-dependent and CsA-sensitive $\downarrow \Delta \Psi \mathrm{m}$ might induce PTP opening and the mitochondrial pathway of apoptosis even in the absence of nuclear signals (6). However, depolarization alone is insufficient to support the hypothesis that AQs might represent a new class of apoptosis-targeted drugs that directly interact with components of the PTP to induce mitochondrial permeability transition (MPT). Critical MPT events result from the sudden and non-specific permeabilization of the inner membrane (IM) to ions and low molecular weight (MW) solutes and the hyperosmolarity of the matrix, including the entry of water from the cytosol, the large amplitude swelling, the rupture of the outer membrane $(\mathrm{OM})$, and the release of sequestered $\mathrm{Ca}^{2+}$. Therefore, as MPT requires more than depolarization to occur, antitumor AQs were tested for their ability to interact with isolated organelles and directly trigger specific markers of MPT, such as mitochondrial swelling and intramitochondrial $\mathrm{Ca}^{2+}$ release.

\section{Materials and methods}

Drug treatments. The methods to synthesize in relatively few steps and high yield the structures of the AQ1 analogs illustrated in Fig. 1 and listed in Table I have already been reported $(4,5)$. These novel antitumor AQs were synthesized and selective functionalization at the $\mathrm{C}$ ring was accomplished by a benzylic bromination reaction. The resulting bromoderivatives were converted into water-soluble and phosphate ester drugs (4,5). All solutions of AQ2 (Aldrich, Milwaukee, WI), synthetic AQ1 analogs, atractyloside, phenylarsine oxide, d-Ub (2,3-dimethoxy-5-methyl-6-decyl-1,4benzoquinone), 2,3-dimethoxy-5-methyl-p-benzoquinone ( $\mathrm{Ub}_{0}$, ubiquinone-0 or coenzyme $\mathrm{Q}_{0}$ ), 2,3-dimethoxy-5-methyl6-(3-methyl-2-butenyl)-1,4-benzoquinone $\left(\mathrm{Ub}_{5}\right.$, ubiquinone5 or coenzyme $\mathrm{Q}_{1}$ ), 2,3-dimethoxy-5-methyl-6-geranyl-1,4benzoquinone $\left(\mathrm{Ub}_{10}\right.$, ubiquinone-10 or coenzyme $\mathrm{Q}_{2}$ ) (all from Sigma, St. Louis, MO) and CsA (Calbiochem, La Jolla, CA) were dissolved and diluted in dimethyl sulfoxide (DMSO). Fluo-5N, pentapotassium salt (Molecular Probes, Eugene, OR), ADP (Sigma), and RR (Fluka, Buchs SG, Switzerland) solutions were prepared in double-distilled water (DDW). Alamethicin (Sigma) was formulated in 50\% EtOH, arsenic(III) oxide (arsenic trioxide; Sigma) was solubilized in $1 \mathrm{~N} \mathrm{NaOH}$ before dilution in DDW, and BA (Sigma) was provided in $10 \mathrm{mM}$ Tris- $\mathrm{HCl}$ buffer, $\mathrm{pH}$ 7.5. All reference anticancer drugs were purchased from Sigma. DAU, doxorubicin (DOX, adriamycin), staurosporine, mitoxantrone, vincristine, vinblastine, etoposide (VP-16), taxol (paclitaxel), nocodazole, tubulozole C, 5-fluorouracil, cis-diammineplatinum (II) dichloride (cisplatin) and camptothecin were all dissolved in DMSO, whereas cytosine B-D-arabinofuranoside (Ara-C) and cyclophosphamide were prepared in DDW and amethopterin (methotrexate; Sigma) was solubilized in $0.1 \mathrm{~N} \mathrm{NaOH}$ before dilution in DDW. The concentrations of these vehicles in the final incubation volumes never exceeded $0.2 \%$ and did not interfere with the data.

Cell cultures and proliferation assays. Suspension cultures of mouse L1210 lymphocytic leukemia, human HL-60 promyelocytic leukemia and mouse LL/2 Lewis lung carcinoma cells (all from ATCC, Manassas, VA) were maintained in continuous exponential growth by twice-a-week passage in RPMI-1640 medium supplemented with $10 \%$ fetal bovine calf serum (Atlanta Biologicals, Norcross, GA) and penicillin $(100 \mathrm{IU} / \mathrm{ml})$-streptomycin $(100 \mu \mathrm{g} / \mathrm{ml})$, and incubated in the presence or absence (control) of drugs at $37^{\circ} \mathrm{C}$ in a humidified 
atmosphere containing $5 \% \mathrm{CO}_{2}(1-3,6)$. The proliferation of drug-treated L1210 (initial density 4.5×103/0.5 ml), HL-60 (initial density $3.75 \times 10^{4} / 0.5 \mathrm{ml}$ ) and LL/2 (initial density $\left.1.75 \times 10^{3} / 0.5 \mathrm{ml}\right)$ tumor cells was assessed from their mitochondrial ability to bioreduce the MTS reagent (Promega, Madison, WI) in the presence of PMS (Sigma) into a watersoluble formazan product that absorbs at $490 \mathrm{~nm}$. After 4 days at $37^{\circ} \mathrm{C}$ in 48 -well Costar cell culture plates, control and drug-treated cell samples $\left(\sim 10^{6} / 0.5 \mathrm{ml} /\right.$ well for controls) were further incubated at $37^{\circ} \mathrm{C}$ for $3 \mathrm{~h}$ in the dark in the presence of $0.1 \mathrm{ml}$ of MTS:PMS (2:0.1) reagent and their relative metabolic activity was estimated by recording the absorbance at $490 \mathrm{~nm}$, using a Cambridge model 750 automatic microplate reader (Packard, Downers Grove, IL). Blank values for culture medium supplemented with MTS:PMS reagent in the absence of cells were substracted from the results $(1-3,6)$.

Isolation of mitochondria. To collect enough organelles to study AQ-induced mitochondrial swelling and $\mathrm{Ca}^{2+}$ release, they were isolated by differential centrifugation at $4^{\circ} \mathrm{C}$ from one female CF-1 (Charles River, Wilmington, MA) mouse liver after an overnight period of fasting to deplete its levels of glycogen and fatty acids (6,7-10). The liver was rinsed, minced with scissors in $10 \mathrm{ml}$ of $10 \mathrm{mM}$ HEPES buffer, pH 7.2, containing $225 \mathrm{mM}$ mannitol, $75 \mathrm{mM}$ sucrose, $1 \mathrm{mM}$ EGTA and $0.1 \% \mathrm{BSA}$, and homogenized in $40 \mathrm{ml}$ of this mitochondrial extraction buffer with two slow up/down strokes of a motorized tight-fitting Teflon pestle rotating at 500 r.p.m. in a glass Potter-Elvejhem tissue grinder. Disrupted cells were centrifuged $(1,000 \mathrm{~g} \mathrm{x} 10 \mathrm{~min})$ in a $50-\mathrm{ml}$ conical polypropylene tube to precipitate unlysed cells, nuclei and large membrane fragments. The supernatant was decanted and then recentrifuged $(10,000 \mathrm{~g} \mathrm{x} 10 \mathrm{~min})$ in $15-\mathrm{ml}$ Corex borosilicate glass tubes to collect the mitochondrial pellets, which were washed, pooled and resuspended at a final concentration of $50 \mathrm{mg}$ protein/ml of mitochondrial storage buffer, containing $10 \mathrm{mM}$ HEPES, pH 7.2, $225 \mathrm{mM}$ mannitol and $75 \mathrm{mM}$ sucrose (6,7-10). The protein concentrations of the mitochondrial samples were determined using the BCA protein assay kit (Pierce, Rockford, IL).

Mitochondrial swelling. Conventional rod-shaped mitochondria are packed with small and dense cristae, whereas large and swollen mitochondria have diluted matrices with cristae in various stages of disintegration. Matrix configuration is determined by light scattering: the more condensed matrices diffract more light (11-13). Since severely swollen mitochondria with clear matrices and disrupted cristae scatter and absorb much less light than the dense and granular lightabsorbing structure of their normal compact counterparts, a decrease in light scattering reflects the degree of mitochondrial swelling. Hence, the large amplitude swelling of mitochondria undergoing AQ-induced MPT was determined spectrophotometrically by monitoring the decrease in apparent absorbance (light-scattering) at $540 \mathrm{~nm}(9,12,13)$. To assay mitochondrial swelling, 24-well Costar clear transparent polystyrene cell culture plates were sequentially supplemented with $1 \mathrm{ml}$ of mitochondrial reaction buffer (MRB), containing $10 \mathrm{mM}$ HEPES, pH 7.2, $100 \mathrm{mM}$ sucrose, $65 \mathrm{mM} \mathrm{KCl,} 5 \mathrm{mM}$

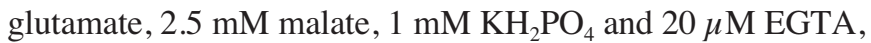
and $30 \mu \mathrm{l}$ of isolated mitochondria (1.5 $\mathrm{mg}$ of protein). After incubation of these control or AQ-treated reaction mixtures for $5 \mathrm{~min}$ at room temperature, the decrease of absorbance (light scattering) linked to large amplitude mitochondrial swelling was monitored for 2.5-30 min at $540 \mathrm{~nm}$, using a Cambridge model 750 automatic microplate reader.

Mitochondrial $\mathrm{Ca}^{2+}$ release. The ability of AQs to directly induce isolated mitochondria to release $\mathrm{Ca}^{2+}$ was determined using the pentapotassium salt of Fluo-5N, a cell-impermeant $\mathrm{Ca}^{2+}$ indicator, which is not fluorescent in the absence of divalent cation but exhibits strong fluorescence upon binding to extramitochondrial $\mathrm{Ca}^{2+}$. Hence, the development of green Fluo-5N fluorescence was linked to the increase of free extramitochondrial $\mathrm{Ca}^{2+}$ in the reaction medium, resulting from the release of sequestered $\mathrm{Ca}^{2+}$ by mitochondria undergoing AQ- or $100 \mu \mathrm{M} \mathrm{Ca}^{2+}$ overload-induced MPT. In controls, the baseline of green Fluo-5N fluorescence is low since the high $\Delta \Psi \mathrm{m}$ prevents the release of mitochondrial $\mathrm{Ca}^{2+}$. Likewise, when $100 \mu \mathrm{M} \mathrm{Ca}^{2+}$ overload is used to trigger MPT, the RRsensitive $\mathrm{Ca}^{2+}$ uniporter accumulates the cation so rapidly into the matrix that Fluo- $5 \mathrm{~N}$ fluorescence returns to baseline before measurements can be made in the microplate reader, but any subsequent increase of Fluo- $5 \mathrm{~N}$ fluorescence demonstrates the release of intramitochondrial $\mathrm{Ca}^{2+}$ caused by AQ- or $100 \mu \mathrm{M} \mathrm{Ca}^{2+}$ overload-induced MPT $(9,14)$. Mitochondrial $\mathrm{Ca}^{2+}$ released was assayed in 1.5-ml Eppendorf tubes, which were sequentially supplemented with $1 \mathrm{ml}$ of MRB, $1 \mu 1$ of dye to obtain a final concentration of $1 \mu \mathrm{M}$ Fluo-5N, and $20 \mu \mathrm{l}$ of isolated mitochondria (1 $\mathrm{mg}$ of protein). After incubation of these control or AQ-treated reaction mixtures for $5 \mathrm{~min}$ at room temperature, $0.2-\mathrm{ml}$ aliquots were transferred to a 96well Costar white opaque polystyrene assay plate and the increased fluorescence of Fluo-5N, which indicates that the membrane impermeable dye is bound to $\mathrm{Ca}^{2+}$ released from mitochondria undergoing MPT, was monitored for 2.5-30 min at $495 \mathrm{~nm}$ excitation/518 $\mathrm{nm}$ emission, using a Cary Eclipse Fluorescence Spectrophotometer equipped with microplate reader accessory (Varian, Walnut Creek, CA) $(9,14)$.

\section{Results}

Inhibition of tumor cell proliferation. The antiproliferative activities of 4 new C6-substituted AQ analogs were compared to those of the current lead antitumor compounds AQ8 and AQ9 (Fig. 1). The nomenclatures of the newly synthesized compounds are: AQ14, 6-glucosaminomethyl-1,4-anthracenedione; AQ15, a hydrogen chloride salt of AQ14; AQ16, 6-quinoylmethyl-1,4-anthracenedione; and AQ17, di-t-butyl[(5,8-dioxo-2-anthracenyl)methyl]phosphate. AQ17, which can be used to prepare water-soluble phosphate ester prodrugs, is nearly equipotent to AQ8 and AQ9 against L1210, HL-60 and LL/2 tumor cell proliferation (Fig. 1). AQ14 and, especially, AQ16 are clearly less effective. Hydrophilic AQ15, which is the least effective against HL-60 cell proliferation, was not further tested in the other tumor cell lines. Because of their potent antitumor effects in vitro, AQ8, AQ9 and AQ17 were selected to study the markers of MPT in isolated mitochondria. 
A.

B.
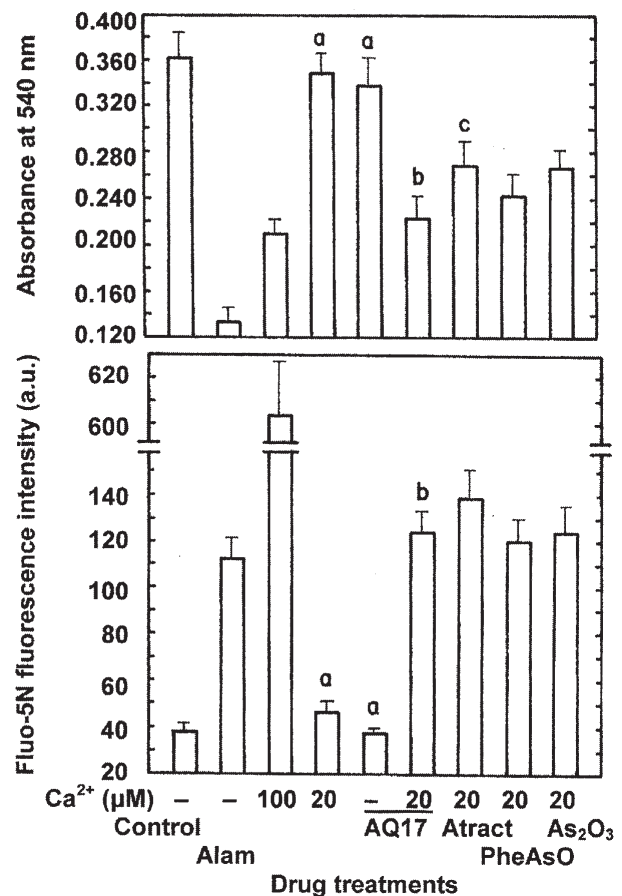

Figure 2. Inducers of MPT in a cell-free system. A, comparison of the abilities

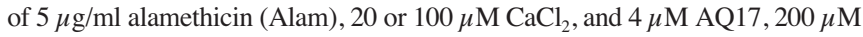
atractyloside (Atract), $5 \mu \mathrm{M}$ phenylarsine oxide (PheAsO) or $100 \mu \mathrm{M}$ arsenic trioxide $\left(\mathrm{As}_{2} \mathrm{O}_{3}\right)$, in the presence of a $20 \mu \mathrm{M} \mathrm{Ca}^{2+}$ primer, to directly induce the large amplitude swelling of isolated mitochondria. The decrease in absorbance (light scattering) at $540 \mathrm{~nm}$ occurs after $15 \mathrm{~min}$ in severely swollen organelles with diluted matrices and disrupted cristae. Control: absorbance at $540 \mathrm{~nm}$ of non-treated suspensions of isolated mitochondria $(0.362 \pm 0.022)$. Bars: means $\pm \mathrm{SD}(\mathrm{n}=3)$. ${ }^{\mathrm{a} N o t}$ different from control; ${ }^{b}$ not different from $100 \mu \mathrm{M} \mathrm{Ca}^{2+}$ or PheAsO but $\mathrm{P}<0.05$, smaller than Atract or $\mathrm{As}_{2} \mathrm{O}_{3}$; ${ }^{\mathrm{c} P}<0.01$, smaller than $20 \mu \mathrm{M} \mathrm{Ca}^{2+}$. $\mathrm{B}$, comparison of the abilities of the above treatments to directly induce the release of $\mathrm{Ca}^{2+}$ sequestered in isolated mitochondria. The development of green Fluo-5N fluorescence (arbitrary units: a.u.) occurs when this membrane impermeable dye, which is not fluorescent in the absence of divalent cation, becomes bound to the extramitochondrial $\mathrm{Ca}^{2+}$ released from these drug-treated organelles at $15 \mathrm{~min}$. Control: baseline intensity of Fluo-5N fluorescence in non-treated suspensions of isolated mitochondria (38.2 \pm 3.4$)$. ${ }^{a}$ Not different from control; ${ }^{\mathrm{b}} \mathrm{P}<0.0005$, greater than $20 \mu \mathrm{M} \mathrm{Ca}^{2+}$ but not different from Alam, Atract, PheAsO or $\mathrm{As}_{2} \mathrm{O}_{3}$.

Induction of MPT. Freshly isolated mitochondria were used to determine whether antitumor AQs would directly target these organelles to induce the large amplitude swelling and release of sequestered $\mathrm{Ca}^{2+}$ that are indicative of MPT. The transmembrane channel-forming peptide alamethicin, which functions as an uncoupler of mitochondrial oxidative phosphorylation by dissipating electrochemical gradients across the IM, is used as a positive control to demonstrate the rapid induction of mitochondrial swelling and $\mathrm{Ca}^{2+}$ release within 15 min (Fig. 2). Since the open-closed transition of the PTP is $\mathrm{Ca}^{2+}$ sensitive and mitochondrial $\mathrm{Ca}^{2+}$ overload triggers PTP opening, IM permeabilization, depolarization, swelling and apoptosis, raising the exogenous concentration of $\mathrm{Ca}^{2+}$ from a low of $20 \mu \mathrm{M}$, which has no effect on its own, to a high of $100 \mu \mathrm{M}$ immediately induces isolated mitochondria to swell and release their sequester $\mathrm{Ca}^{2+}$ (Fig. 2). Interestingly, $4 \mu \mathrm{M}$ AQ17, which is inactive alone, requires the presence of a

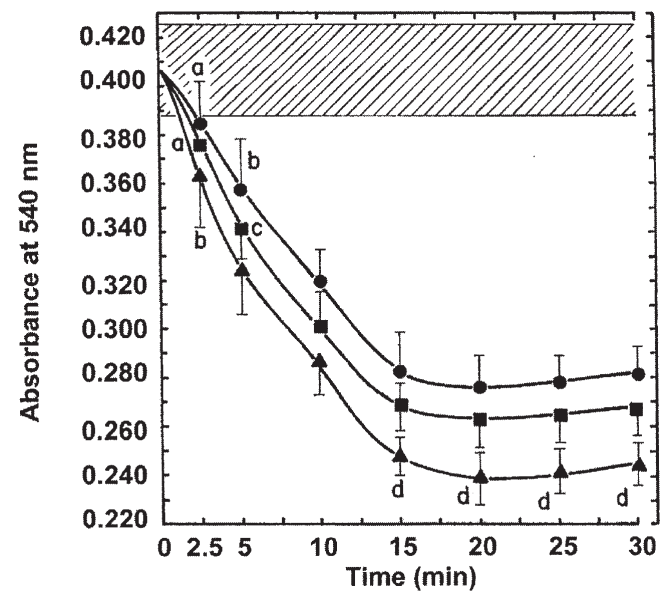

Figure 3. Comparison of the time-dependent inductions of the large amplitude swelling of isolated mitochondria by $4 \mu \mathrm{M}$ concentrations of AQ8 (•), AQ9 (घ) or AQ17 ( $\mathbf{\Delta})$, in the presence of a $20 \mu \mathrm{M} \mathrm{Ca}^{2+}$ primer. Control: average absorbance at $540 \mathrm{~nm}$ of non-treated suspensions of isolated mitochondria at all time points studied $\left(0.407 \pm 0.019\right.$; striped area). Alone, $20 \mu \mathrm{M} \mathrm{Ca}^{2+}$ is unable to induce mitochondrial swelling over $30 \mathrm{~min}(0.390 \pm 0.015$, not different from control), whereas a $100 \mu \mathrm{M} \mathrm{Ca}^{2+}$ overload does within 5-10 min and is used as a reference MPT-inducing treatment $(0.237 \pm 0.009)$. Bars: means $\pm \mathrm{SD}(\mathrm{n}=3)$. ${ }^{\mathrm{a}}$ Not different from control; ${ }^{\mathrm{b}}<0.05$ and ${ }^{\mathrm{c}} \mathrm{P}<0.025$, smaller than control; ${ }^{\mathrm{d}} \mathrm{P}<0.05$, smaller than AQ9.

$20 \mu \mathrm{M} \mathrm{Ca}^{2+}$ primer in order to induce the same mitochondrial swelling and $\mathrm{Ca}^{2+}$ release at $15 \mathrm{~min}$ as those caused by $100 \mu \mathrm{M}$ $\mathrm{Ca}^{2+}$ overload or other known MPT inducers, including $200 \mu \mathrm{M}$ atractyloside, $5 \mu \mathrm{M}$ phenylarsine oxide and $100 \mu \mathrm{M}$ arsenic trioxide (Fig. 2). Antitumor AQs, therefore, might interact with the PTP to induce conformational changes that increase its sensitivity to the priming concentration of $20 \mu \mathrm{M} \mathrm{Ca}^{2+}$ and trigger its transition to the open state.

Characterization of AQ-induced MPT. The ability of AQ8, AQ9 and AQ17 to induce $\mathrm{Ca}^{2+}$-dependent MPT in isolated mitochondria is a function of time (Fig. 3) and concentration (Fig. 4). At a concentration of $4 \mu \mathrm{M}, \mathrm{AQ} 8, \mathrm{AQ} 9$ and AQ17 need about $15 \mathrm{~min}$ to fully induce mitochondrial swelling (Fig. 3). The $\mathrm{Ca}^{2+}$-dependent mitochondrial swelling induced by AQ17 is slightly greater than those caused by AQ8 and AQ9, starting earlier at $2.5 \mathrm{~min}$ and reaching a larger amplitude at $15 \mathrm{~min}$ (Fig. 3). When compared at $15 \mathrm{~min}$, the $\mathrm{Ca}^{2+}$ dependent inductions of mitochondrial swelling and $\mathrm{Ca}^{2+}$ release by AQ8, AQ9 and AQ17 are similarly concentration dependent, starting at $\sim 256-640 \mathrm{nM}$ and peaking at $4 \mu \mathrm{M}$ before declining thereafter (Fig. 4). Again, AQ17 appears to be a slightly more potent MPT inducer than AQ8 and/or AQ9 (Fig. 4).

Relevance of $A Q$-induced MPT. In general, synthetic AQ analogs seem to induce markers of MPT in isolated mitochondria in relation with their antiproliferative and proapoptotic effects in tumor cells in vitro (1-6). AQ2 and 6,7-dichloro-1,4-dihydroxy-9,10-anthracenedione (AQ3), which have an internal quinoid ring, and 6,7-dichloro-2(methylamino)-1,4-anthracenedione hydrochloride (AQ5), 6,7-dichloro-2-(methylamino)-1,4-anthracenedione (AQ6) and 2-(methylamino)-1,4-anthracenedione (AQ7), which 
A.

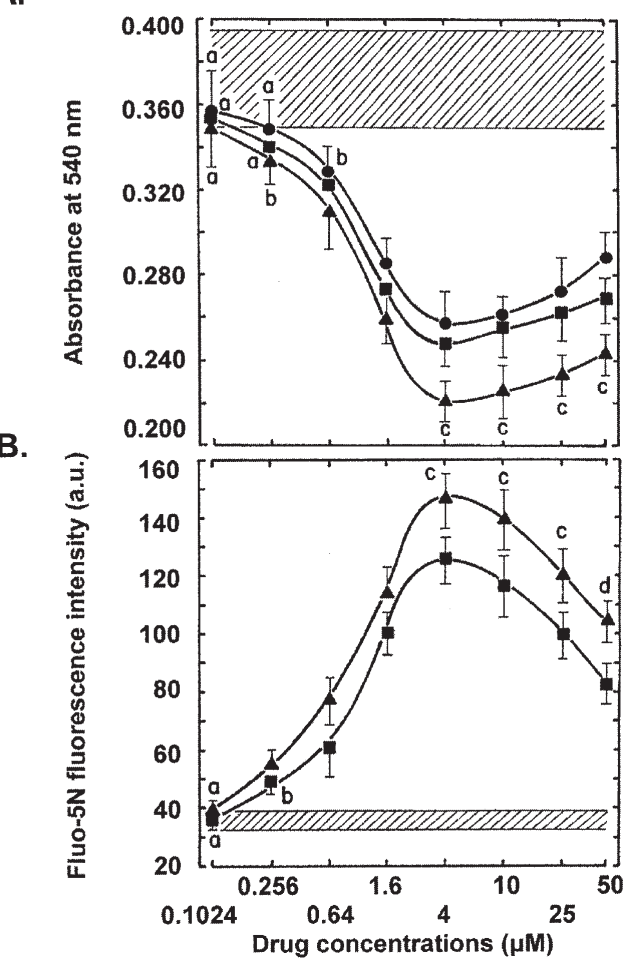

Figure 4. Concentration-dependent induction of MPT by AQs in a cell-free system. A, comparison of the abilities of serial concentrations (plotted on a

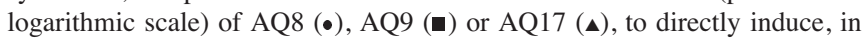
the presence of a $20 \mu \mathrm{M} \mathrm{Ca}^{2+}$ primer, the large amplitude swelling of isolated mitochondria after $15 \mathrm{~min}$. Control: absorbance at $540 \mathrm{~nm}$ of non-treated suspensions of isolated mitochondria $(0.372 \pm 0.023$, striped area). Alone, $20 \mu \mathrm{M} \mathrm{Ca}^{2+}$ is unable to induce mitochondrial swelling $(0.357 \pm 0.021$, not different from control), whereas a $100 \mu \mathrm{M} \mathrm{Ca}^{2+}$ overload does and is used as a reference MPT-inducing treatment $(0.232 \pm 0.009)$. Bars: means $\pm \mathrm{SD}(\mathrm{n}=3)$. ${ }^{a}$ Not different from control; ${ }^{b} \mathrm{P}<0.05$, smaller than control; ${ }^{\mathrm{c}} \mathrm{P}<0.05$, smaller than AQ9. B, comparison of the abilities of serial concentrations of AQ9 (घ) or AQ17 (ي), to directly induce, in the presence of a $20 \mu \mathrm{M} \mathrm{Ca}^{2+}$ primer, the release of $\mathrm{Ca}^{2+}$ from isolated mitochondria after $15 \mathrm{~min}$. Control: baseline intensity of Fluo-5N fluorescence in non-treated suspensions of isolated mitochondria (35.9 \pm 2.9 , striped area). Alone, $20 \mu \mathrm{M} \mathrm{Ca}^{2+}$ does not trigger mitochondrial $\mathrm{Ca}^{2+}$ release $(43.1 \pm 3.8$, not different from control), whereas a $100 \mu \mathrm{M} \mathrm{Ca}^{2+}$ overload does and is used as a reference MPT-inducing treatment (581.0 \pm 32.5$)$. ${ }^{a}$ Not different from control; ${ }^{\mathrm{b}} \mathrm{P}<0.025$, greater than control; ${ }^{\mathrm{c}} \mathrm{P}<0.05$ and ${ }^{\mathrm{d}} \mathrm{P}<0.025$, greater than $\mathrm{AQ9}$.

have a substituent on their external quinone ring, and 5,8dioxo-5,8-dihydro-2-anthracenecarboxylic acid (AQ13), which has a carboxylic acid function, have no antitumor effects and all fail to induce mitochondrial swelling in presence of a $20 \mu \mathrm{M} \mathrm{Ca}^{2+}$ primer (Table I). In contrast, $4 \mu \mathrm{M}$ concentrations of the potent antitumor compounds AQ1, AQ8, AQ9, AQ10 and AQ17 all mimic the MPT-inducing effect of a $100 \mu \mathrm{M}$ $\mathrm{Ca}^{2+}$ overload in isolated mitochondria and induce the most $\mathrm{Ca}^{2+}$-dependent mitochondrial swelling and $\mathrm{Ca}^{2+}$ release at 15 min (Table I). Other compounds with weak or moderate antitumor activities, such as 6,7-dichloro-1,4-anthracenedione (AQ4), 6-formyl-1,4-anthracenedione (AQ11), a mixture of 2-bromo-6-methyl- and 2-bromo-7-methyl-1,4-anthracenedione regioisomers (AQ12), AQ14 and AQ16, only partially induce $\mathrm{Ca}^{2+}$-dependent swelling and intramitochondrial $\mathrm{Ca}^{2+}$ release in a population of isolated mitochondria (Table I). Antitumor AQs may have a unique ability to directly interact with isolated mitochondria and trigger MPT since various other anticancer
Table II. Comparison of the direct MPT-inducing activities of known antiproliferative and anticancer drugs in isolated mitochondria.

\begin{tabular}{|c|c|c|}
\hline \multirow[t]{2}{*}{ Treatment $^{\mathrm{a}}$} & \multicolumn{2}{|c|}{ Markers of MPT in isolated mitochondria } \\
\hline & $\begin{array}{c}\text { Swelling } \\
\text { Absorbance at } \\
540 \mathrm{~nm}^{\mathrm{b}}\end{array}$ & $\begin{array}{l}\mathrm{Ca}^{2+} \text { release } \\
\text { Fluo-5N fluorescence } \\
\text { intensity (a.u. })^{\mathrm{b}}\end{array}$ \\
\hline Control & $0.305 \pm 0.015$ & $36.8 \pm 2.1$ \\
\hline $100 \mu \mathrm{M} \mathrm{Ca}^{2+}$ & $0.185 \pm 0.008$ & $557.2 \pm 31.7$ \\
\hline $20 \mu \mathrm{M} \mathrm{Ca}^{2+}$ & $0.292 \pm 0.016^{\mathrm{c}}$ & $41.1 \pm 3.3^{c}$ \\
\hline + Daunorubicin & $0.329 \pm 0.022^{\mathrm{d}}$ & $29.1 \pm 2.3^{\mathrm{e}}$ \\
\hline + Doxorubicin & $0.321 \pm 0.019^{\mathrm{d}}$ & $33.5 \pm 2.3^{\mathrm{f}}$ \\
\hline+ Staurosporine & $0.283 \pm 0.012^{\mathrm{d}}$ & $42.2 \pm 2.8^{\mathrm{d}}$ \\
\hline + Mitoxantrone & $0.313 \pm 0.016^{\mathrm{d}}$ & $35.5 \pm 2.5^{\mathrm{d}}$ \\
\hline + Vincristine & $0.290 \pm 0.017^{\mathrm{d}}$ & $40.7 \pm 2.2^{\mathrm{d}}$ \\
\hline+ Vinblastine & $0.291 \pm 0.011^{\mathrm{d}}$ & $41.1 \pm 2.4^{\mathrm{d}}$ \\
\hline + Etoposide (VP-16) & $0.288 \pm 0.015^{\mathrm{d}}$ & $46.7 \pm 3.4^{\mathrm{d}}$ \\
\hline+ Taxol & $0.291 \pm 0.017^{\mathrm{d}}$ & $41.5 \pm 2.7^{\mathrm{d}}$ \\
\hline + Nocodazole & $0.287 \pm 0.011^{\mathrm{d}}$ & $40.4 \pm 2.3^{\mathrm{d}}$ \\
\hline + Tubulozole $\mathrm{C}$ & $0.303 \pm 0.011^{\mathrm{d}}$ & $60.7 \pm 5.3^{\mathrm{g}}$ \\
\hline + Methotrexate & $0.290 \pm 0.013^{\mathrm{d}}$ & $39.3 \pm 2.6^{\mathrm{d}}$ \\
\hline+ Ara-C & $0.289 \pm 0.012^{\mathrm{d}}$ & $41.8 \pm 3.0^{\mathrm{d}}$ \\
\hline +5-Fluorouracil & $0.286 \pm 0.015^{\mathrm{d}}$ & $40.4 \pm 2.5^{\mathrm{d}}$ \\
\hline + Cyclophosphamide & $0.304 \pm 0.011^{\mathrm{d}}$ & $39.6 \pm 2.2^{\mathrm{d}}$ \\
\hline + Cisplatin & $0.302 \pm 0.012^{\mathrm{d}}$ & $40.1 \pm 2.2^{\mathrm{d}}$ \\
\hline + Camptothecin & $0.288 \pm 0.014^{\mathrm{d}}$ & $40.8 \pm 2.4^{\mathrm{d}}$ \\
\hline
\end{tabular}

Isolated mitochondria were incubated for $15 \mathrm{~min}$ with $4-\mu \mathrm{M}$ concentrations of drugs in the presence of a $20 \mu \mathrm{M} \mathrm{Ca}^{2+}$ primer; ${ }^{b}$ means $\pm \mathrm{SD}(\mathrm{n}=3)$; ${ }^{\mathrm{c}}$ not different from control; ${ }^{\mathrm{d}}$ not different from $20 \mu \mathrm{M} \mathrm{Ca}^{2+}$; ${ }^{\mathrm{P}}<0.01$ and ${ }^{\mathrm{f}} \mathrm{P}<0.05$, smaller than $20 \mu \mathrm{M} \mathrm{Ca}^{2+} ;{ }^{\mathrm{g}} \mathrm{P}<0.01$, greater than $20 \mu \mathrm{M} \mathrm{Ca}^{2+}$

drugs tested at $4 \mu \mathrm{M}$ under similar conditions all fail to induce $\mathrm{Ca}^{2+}$-dependent mitochondrial swelling and $\mathrm{Ca}^{2+}$ release at $15 \mathrm{~min}$ (Table II). This wide spectrum of known DNA-alkylating and -damaging agents, DNA topoisomerase inhibitors, microtubule-interacting compounds and antimetabolites tested over the $0.256-25 \mu \mathrm{M}$ range is also unable to trigger markers of MPT in isolated mitochondria within $1 \mathrm{~h}$ (data not shown).

Inhibition of $A Q$-induced MPT. The hypothesis that antitumor AQs might directly interact with components of the PTP to increase its $\mathrm{Ca}^{2+}$ sensitivity and trigger its opening is substantiated by the fact that a low and normally ineffective $20 \mu \mathrm{M} \mathrm{Ca}^{2+}$ concentration of exogenous $\mathrm{Ca}^{2+}$ now becomes sufficient to prime AQ-induced mitochondrial swelling and $\mathrm{Ca}^{2+}$ release (Fig. 5). As expected, this $\mathrm{Ca}^{2+}$-dependent induction of mitochondrial swelling and $\mathrm{Ca}^{2+}$ release by $4 \mu \mathrm{M}$ AQ17 is abolished by $0.1 \mu \mathrm{M}$ RR, which blocks the $\mathrm{Ca}^{2+}$ uniporter (Fig. 5). The ability of $4 \mu \mathrm{M}$ AQ17 to directly trigger mitochondrial swelling and $\mathrm{Ca}^{2+}$ release in the presence of a $20 \mu \mathrm{M} \mathrm{Ca}^{2+}$ primer is also abolished or inhibited by several MPT blockers known to interact with various components of the PTP complex to prevent its opening. These inhibitors 
A.

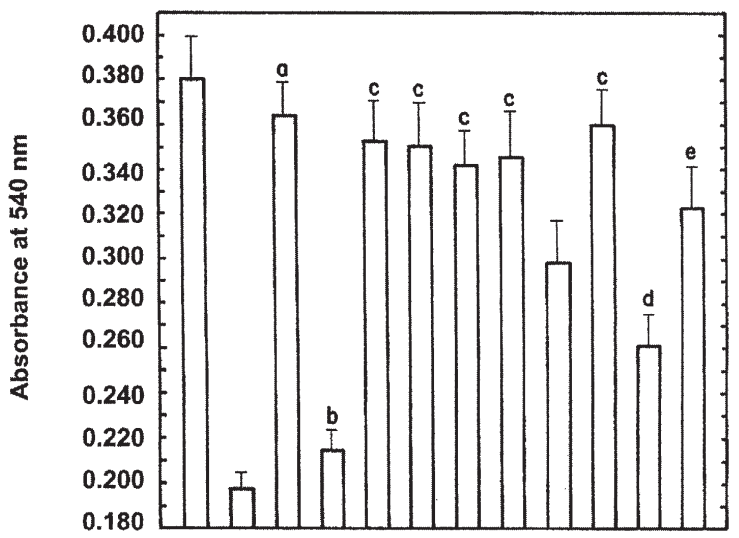

B.

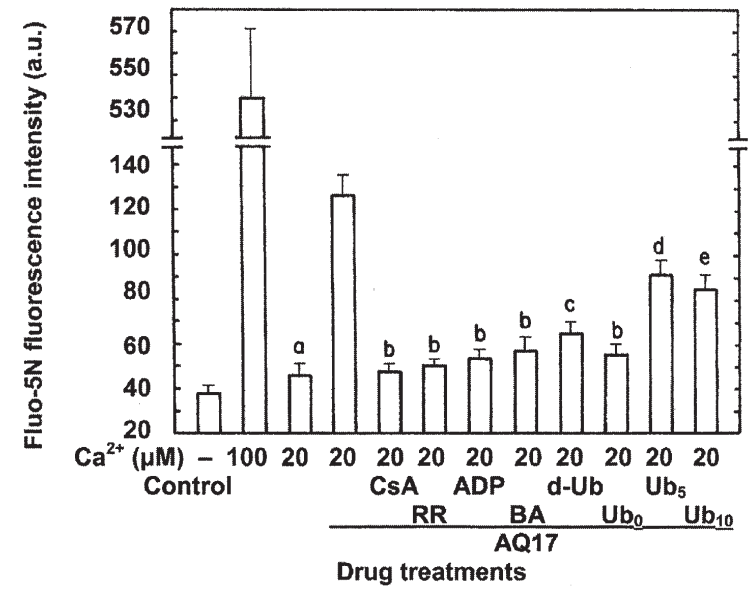

Figure 5. Inhibition of AQ-induced MPT in a cell-free system. A, comparison of the abilities of $1 \mu \mathrm{M}$ CsA, $0.1 \mu \mathrm{M}$ RR, 2 mM ADP, $20 \mu \mathrm{M}$ BA, $100 \mu \mathrm{M}$ d-Ub, $50 \mu \mathrm{M} \mathrm{Ub}_{0}, 100 \mu \mathrm{M} \mathrm{Ub}_{5}$ or $100 \mu \mathrm{M} \mathrm{Ub}_{10}$ pretreatments to inhibit the large amplitude swelling of isolated mitochondria directly induced after $15 \min$ by $4 \mu \mathrm{M}$ AQ17 in the presence of a $20 \mu \mathrm{M} \mathrm{Ca}^{2+}$ primer. Control: absorbance at $540 \mathrm{~nm}$ of non-treated suspensions of isolated mitochondria $(0.380 \pm 0.019)$. Alone, $20 \mu \mathrm{M} \mathrm{Ca}^{2+}$ is unable to induce mitochondrial swelling, whereas a $100 \mu \mathrm{M} \mathrm{Ca}^{2+}$ overload does and is used as a reference MPTinducing treatment. Bars: means $\pm \mathrm{SD}(\mathrm{n}=3)$. ${ }^{\mathrm{a}}$ Not different from control; ${ }^{\mathrm{b}}$ not different from $100 \mu \mathrm{M} \mathrm{Ca}^{2+}$; ${ }^{\mathrm{c}}$ not different from $20 \mu \mathrm{M} \mathrm{Ca}^{2+} ;{ }^{\mathrm{d}} \mathrm{P}<0.01$, greater than $20 \mu \mathrm{M} \mathrm{Ca}^{2+}+4 \mu \mathrm{M} \mathrm{AQ17;}{ }^{\mathrm{e}}<0.05$, smaller than $20 \mu \mathrm{M} \mathrm{Ca}^{2+}$. $\mathrm{B}$, comparison of the abilities of the above pretreatments to inhibit the release of $\mathrm{Ca}^{2+}$ from isolated mitochondria directly induced after $15 \mathrm{~min}$ by $4 \mu \mathrm{M}$ AQ17 in the presence of a $20 \mu \mathrm{M} \mathrm{Ca}^{2+}$ primer. Control: baseline intensity of Fluo-5N fluorescence in non-treated suspensions of isolated mitochondria (37.9 \pm 3.1$)$. Alone, $20 \mu \mathrm{M} \mathrm{Ca}^{2+}$ does not trigger mitochondrial $\mathrm{Ca}^{2+}$ release, whereas a $100 \mu \mathrm{M} \mathrm{Ca}^{2+}$ overload does and is used as a reference MPT-inducing treatment. ${ }^{a}$ Not different from control; ${ }^{b}$ not different from $20 \mu \mathrm{M} \mathrm{Ca}^{2+}$; ${ }^{\mathrm{C}}<0.01$, greater than $20 \mu \mathrm{M} \mathrm{Ca}^{2+}$; ${ }^{\mathrm{d}} \mathrm{P}<0.01$ and ${ }^{\mathrm{e}} \mathrm{P}<0.005$, smaller than $20 \mu \mathrm{M} \mathrm{Ca}^{2+}+4 \mu \mathrm{M}$ AQ17.

of AQ-induced MPT include $1 \mu \mathrm{M}$ CsA, which binds to cyclophilin D, $2 \mathrm{mM}$ ADP and $20 \mu \mathrm{M}$ BA, the natural and synthetic ligands that stabilize the adenine nucleotide translocator (ANT) in an inactive conformation, and $100 \mu \mathrm{M} \mathrm{d}-\mathrm{Ub}$, $50 \mu \mathrm{M} \mathrm{Ub}_{0}, 100 \mu \mathrm{M} \mathrm{Ub}_{5}$ and $100 \mu \mathrm{M} \mathrm{Ub}_{10}$, which interact with the ubiquinone (Ub)/quinone-binding site of the PTP to induce conformational changes that decrease its $\mathrm{Ca}^{2+}$ sensitivity (Fig. 5).

\section{Discussion}

The PTP functions as a CsA-sensitive and $\mathrm{Ca}^{2+}-$, voltage-, $\mathrm{pH}-$ and redox-gated channel with several levels of conductance
(15). The intrinsically low permeability of the IM to ions and solutes allows energy conservation in the form of a protondriven $\Delta \Psi \mathrm{m}$. The primary event in MPT is a sudden and nonspecific permeabilization of the IM to $\mathrm{K}^{+}, \mathrm{Mg}^{2+}$ and $\mathrm{Ca}^{2+}$ as well as to solutes of MW $<1,500 \mathrm{Da}(15,16)$. Once PTP is open, the electrochemical $\mathrm{H}^{+}$gradient essential for oxidative phosphorylation is dissipated, the $\downarrow \Delta \Psi \mathrm{m}$ and uncoupling of respiration deplete ATP levels, and the hyperosmolarity of the matrix induces $\mathrm{H}_{2} \mathrm{O}$ to enter from the cytosol and cause rapid mitochondrial swelling, which may rupture the $\mathrm{OM}$ and trigger the release of intramitochondrial $\mathrm{Ca}^{2+}$ and proapoptotic proteins (17-18).

PTP opening may be regulated by the $\downarrow \Delta \Psi \mathrm{m}$ and the $\mathrm{pH}$ of the matrix but the relationships between depolarization, MPT and apoptosis remain unclear. Even though antitumor AQs trigger mitochondrial depolarization in cells and cellfree systems (6), the $\downarrow \Delta \Psi \mathrm{m}$ may be critical but not sufficient for, or a universal step in, apoptotis (19). MPT is always followed by $\downarrow \Delta \Psi \mathrm{m}$ but $\downarrow \Delta \Psi \mathrm{m}$ is not always followed by MPT (15). Direct $\downarrow \Delta \Psi \mathrm{m}$ caused by CCCP does not induce MPT per se. As MPT requires more than $\downarrow \Delta \Psi \mathrm{m}$ to occur (17), the present findings that antitumor AQs directly induce isolated mitochondria to undergo large amplitude swelling and release their sequestered $\mathrm{Ca}^{2+}$ demonstrate that these depolarizing agents are truly capable of rapidly triggering specific markers of MPT.

PTP opening may induce hyperosmolarity of the matrix, which expands. Swelling resulting from solute and $\mathrm{H}_{2} \mathrm{O}$ flux from intermembrane space to matrix occurs when there is an osmotic imbalance, but not for very short periods of PTP opening or for lower conductance states of MPT. Low concentrations of pore-impermeant solutes may prevent MPT-dependent swelling in vitro. Whether swelling and OM rupture occur after AQ-induced MPT in vivo is hard to predict because of the high level of macromolecules in the cytosol (15). An RR-sensitive uniporter driven by the $\Delta \Psi \mathrm{m}$ of the IM is responsible for $\mathrm{Ca}^{2+}$ uptake (15). Although it is also stored in the endoplasmic reticulum, $\mathrm{Ca}^{2+}$ is mostly sequestered in mitochondria and MPT-induced $\mathrm{Ca}^{2+}$ release is a signal of apoptosis $(14,16) . \mathrm{Ca}^{2+}$ may be released from mitochondria under stress by drugs or $\mathrm{Ca}^{2+}$ overloads that open the CsA-sensitive PTP and cause IM permeabilization, $\downarrow \Delta \Psi \mathrm{m}$ and swelling $(16,20,21)$. The IM contains separate routes for $\mathrm{Ca}^{2+}$ uptake and release. MPT exhibits a prominent $\mathrm{Ca}^{2+}$ dependence. When $\mathrm{Ca}^{2+}$ concentration gradients exist between matrix and cytosol or external medium, onset of MPT serves as a mitochondrial $\mathrm{Ca}^{2+}$ release channel (15). The facts that all the MPT effects of AQs on isolated organelles require a $20 \mu \mathrm{M} \mathrm{Ca}^{2+}$ primer and an active $\mathrm{Ca}^{2+}$ uniporter suggest that these antitumor drugs are likely to lower the threshold of exogenous $\mathrm{Ca}^{2+}$ triggering mitochondrial PTP opening, $\downarrow \Delta \Psi \mathrm{m}$, swelling and $\mathrm{Ca}^{2+}$ release. Presumably, the intracellular concentration of $\mathrm{Ca}^{2+}$ in HL-60 cells might be sufficient to mediate the rapid $\downarrow \Delta \Psi \mathrm{m}$ caused by AQs in mitochondria in situ (6).

The ability of antitumor AQs to target mitochondria and rapidly induce the $\downarrow \Delta \Psi \mathrm{m}$ has been demonstrated in both cultured HL-60 cells and suspensions of freshly isolated mitochondria and is not a fluorescence artifact (6). Indeed, when emission wavelengths are scanned over a 513-713 nm 
range at the 503-nm excitation wavelength of the Rh 123 assay, antitumor AQs alone have no autofluorescence and do not displace the sharp peak of $\mathrm{Rh} 123$ fluorescence at 520-530 nm either in the presence or absence of isolated mitochondria. But, obviously, these AQs increase the fluorescence intensity of the unquenched $\mathrm{Rh} 123$ released solely in the presence of organelles undergoing PTP opening, thereby confirming the validity of our $\downarrow \Delta \Psi \mathrm{m}$ data and ruling out any non-physiological drug-dye interference in the cell-free system (6). Similarly, when emission wavelengths are scanned at the 495 excitation wavelength of the Fluo-5N assay, antitumor AQs do not emit their own fluorescence or interfere with the basal level of Fluo-5N fluorescence when mitochondria are incubated in the absence of a $20 \mu \mathrm{M} \mathrm{Ca}^{2+}$ primer. However, AQs clearly boost the peak of Fluo-5N fluorescence emitted at $518 \mathrm{~nm}$ when the membrane-impermeant dye binds the $\mathrm{Ca}^{2+}$ suddenly released from mitochondria undergoing $\mathrm{Ca}^{2+}$ primer-dependent PTP opening. Moreover, the most convincing evidence that antitumor AQs directly interact with isolated mitochondria to cause PTP opening and MPT is that, under the same experimental conditions where they trigger $\downarrow \Delta \Psi \mathrm{m}$ and $\mathrm{Ca}^{2+}$ release, they rapidly induce large amplitude swelling within $15 \mathrm{~min}$ in a simple spectrophotometric assay where no fluorescent dye is used and no fluorescence artifact is possible.

Since synthetic AQs directly interact with isolated mitochondria to rapidly induce MPT events involved in apoptosis, these new quinone antitumor drugs might have a wider spectrum of molecular targets than DAU, bypass upstream mechanisms of MDR and lead to the development of apoptosistargeted therapies for cancer (22-28). Direct MPT might release proapoptotic molecules independently from the Bcl-2 alterations involved in MDR. Lonidamine triggers $\downarrow \Delta \Psi \mathrm{m}$, Cyt $c$ release and apoptosis by a mechanism which directly targets mitochondria and bypasses MDR in DOX-resistant cells. Betulinic acid triggers apoptosis by a direct effect on mitochondria, which is caspase-independent, bypasses the requirement for upstream signaling and persists in tumor cells that have defective apoptotic pathways (7). In contrast to DAU, DOX, cisplatin and VP-16, which do not rapidly target isolated mitochondria $(7,29)$, AQs irreversibly induce mitochondria to lose their $\Delta \Psi \mathrm{m}$ in a caspase-independent manner within 5-15 min in cell and cell-free systems, suggesting that, no matter what other cellular and nuclear interactions or signaling pathways they generate, AQs also have the potential to directly target this key organelle to initiate MPT and apoptosis (6). The reports that mitochondria isolated from cells previously treated for $12-48 \mathrm{~h}$ with $\mu \mathrm{M}$ concentrations of DOX or other DNA-damaging drugs are severely impaired are totally different and suggest that, in contrast to AQs, indirect and delayed damage to mitochondria in situ is the consequence rather than the cause of DOX-induced cytotoxicity $(7,30,31)$. For instance, the $\downarrow \Delta \Psi \mathrm{m}$ is only observed $2-6 \mathrm{~h}$ after $75-100 \mu \mathrm{M}$ echinocystic acid, 3-6 $\mathrm{h}$ after $25 \mu \mathrm{M}$ parthenolide, 6-48 $\mathrm{h}$ after $50 \mu \mathrm{M}$ cisplatin, $9 \mathrm{~h}$ after $10 \mu \mathrm{M}$ of the carbazole compound LCY-2-CHO, $12 \mathrm{~h}$ after $80 \mu \mathrm{M}$ myricetin, and $24 \mathrm{~h}$ after 2$5 \mu \mathrm{M}$ taxol or $20 \mu \mathrm{M}$ lovastatin (32-38). Moreover, $5 \mu \mathrm{M}$ camptothecin and $100 \mu \mathrm{M}$ tert-butyl hydroperoxide cause mitochondrial hyperpolarization at $1 \mathrm{~h}$ and need $2.5-5 \mathrm{~h}$ or $4-6 \mathrm{~h}$, respectively, to induce the $\downarrow \Delta \Psi \mathrm{m}(39,40)$. Similarly, $500 \mu \mathrm{M}$ VP-16 must be used to detect rapid MPT events in isolated mitochondria, whereas lower concentrations of VP-16 require $24-48 \mathrm{~h}$ to promote cellular apoptosis (10). The fact that AQ-induced $\downarrow \Delta \Psi \mathrm{m}$, swelling and $\mathrm{Ca}^{2+}$ release in isolated mitochondria are blocked by CsA, ADP, BA and various Ubs suggests that antitumor AQs directly interact with components of the PTP complex to cause MPT. The direct action of AQs resembles that of hyperforin, which can induce a rapid and caspase-independent $\downarrow \Delta \Psi \mathrm{m}$ within $30 \mathrm{~min}$, whereas the delayed $\downarrow \Delta \Psi \mathrm{m}$ observed $24-48 \mathrm{~h}$ after paclitaxel is merely the consequence of earlier cytotoxic drug interactions (41). Since the supernatant from drug-treated isolated mitochondria is sufficient to induce apoptotic chromatin condensation in isolated nuclei, rapid execution of apoptosis is nucleus independent but involves mitochondria and CsA-sensitive MPT (42). As PTP-targeting drugs, AQs might be useful cancer cell death inducers when classic drugs requiring nuclear action lose their therapeutic efficacy. Because various topoisomerase inhibitors, microtubule-disrupting compounds, antimetabolites and alkylating agents fail to mimic the rapid $\downarrow \Delta \Psi \mathrm{m}(6)$, swelling and $\mathrm{Ca}^{2+}$ release caused by AQs in our cell and cellfree systems, most of the current anticancer drugs do not have the option of directly targeting mitochondria like AQs but must first damage other molecular targets in order to generate the signals that trigger the mitochondrial pathway of apoptosis.

Since tumor cell mitochondria play a central role in apoptosis, have elevated resting $\Delta \Psi \mathrm{m}$ as their metabolism shifts from phosphorylating to non-phosphorylating conditions, and may be highly susceptible to depolarizing lipophilic cations that partition across the IM, they might be preferentially targeted by antitumor AQs that cause $\downarrow \Delta \Psi \mathrm{m}$, swelling and $\mathrm{Ca}^{2+}$ release (25). However, the role and importance of mitochondrial interaction for the antitumor action of AQs remain to be determined. In general, the most antiproliferative AQs induce the highest MPT responses but structure-activity relationships are difficult to study when mitochondrial $\downarrow \Delta \Psi \mathrm{m}$, swelling and $\mathrm{Ca}^{2+}$ release are likely to be all-or-nothing events, based on the sensitivity threshold of individual mitochondria. Hence, different AQs with increasing antitumor activities are probably targeting an increasing fraction of organelles in the population of isolated mitochondria rather than increasing the MPT responses of individual organelles.

Since drug effectiveness is generally a combination of concentration and duration of action, the apparent discrepancy between the $\mu \mathrm{M}$ concentrations of AQs triggering markers of MPT at 15 min and the $\mathrm{nM}$ concentrations of AQs inhibiting tumor cell proliferation at 4 days is not unusual and does not necessarily imply that rapid mitochondrial dysfunction is irrelevant to the molecular mechanism of antitumor activity. The 0.64-4 $\mu \mathrm{M}$ concentrations of AQs required to trigger mitochondrial $\downarrow \Delta \Psi \mathrm{m}$, swelling and $\mathrm{Ca}^{2+}$ at $15 \mathrm{~min}$ are not different from the ones required to block nucleoside transport at $15 \mathrm{~min}$, inhibit DNA, RNA and protein syntheses at 2-3 h, detect caspase activation, Cyt $c$ release and PARP-1 cleavage at $6 \mathrm{~h}$, and cause internucleosomal DNA fragmentation at $24 \mathrm{~h}$, whereas low 23-140 nM concentrations of AQs added to cell cultures at time 0 are sufficient to decrease tumor cell proliferation after 4 days (1-6). DAU and other established anticancer drugs also require $\mu \mathrm{M}$ concentrations to rapidly induce DNA damage, macromolecule synthesis inhibition and proapoptotic effects, whereas $\mathrm{nM}$ concentrations of these 
drugs, which need several days to reveal their antiproliferative potency, are unable to induce detectable alterations of such early molecular targets within minutes or hours (1-6).

The main components of the PTP complex are the voltagedependent anion channel (VDAC) and ANT which, at the contact sites between the mitochondrial OM and IM, form dynamic megachannels that link the matrix to the cytosol $(23,26,43,44)$. In the OM, the gating of the VDAC may be regulated by interactions with the peripheral benzodiazepine receptor, cytosolic hexokinase II, and Bcl-2 family members that control apoptosis (45-47). Apart from Cyt $c$, the mitochondrial intermembrane space (IMS) contains creatine kinase and other proapoptotic molecules, such as apoptosis-inducing factor (AIF), endonuclease G, Smac/Diablo and htrA2/Omi. The IM contains ANT, which may be regulated by interactions with cyclophilin D, Bcl-2 and Bax, high amounts of cardiolipin, which ensure membrane fluidity and Cyt $c$ oxidase function, and the electron-transporting complexes (I-V) of the mitochondrial respiratory chain, which pump protons out of the matrix to the IMS to generate the $\Delta \Psi \mathrm{m}$ that drives the conversion of ADP to ATP (48). The vital exchange of matrix ATP for cytosolic ADP is dependent on the activity of the ANT-VDAC complex linking the IM to the OM (43). Normally, antiapoptotic Bcl-2 and $\mathrm{Bcl}-\mathrm{x}_{\mathrm{L}}$ might maintain the VDAC in a physiological open state, which allows ATP-ADP exchanges and energy production but is not permeable to Cyt $c$ (43). Conversely, proapoptotic Bax and Bak might disrupt VDAC conformation to induce a nonphysiological open state, which permits the release of Cyt $c$ and other soluble proteins from the IMS (43). Opening of mitochondrial PTP and channels controlled by Bcl-2 family members combined with osmotic swelling of the matrix and rupture of the OM may cause a 2-step release of apoptogenic proteins from the IMS to the cytosol and nucleus $(15,45)$. But the mechanisms of Cyt $c$ release are complex and unclear $(46,49)$. Cyt $c$ release is a universal event in apoptosis but this can occur before, independently, or in the absence of $\downarrow \Delta \Psi \mathrm{m}$ and without concomitant PTP opening, mitochondrial swelling and OM rupture $(19,43,50-56)$. CsA inhibits Cyt $c$ release in isolated mitochondria but not in tumor cells (29), suggesting that some drugs might directly target mitochondria to release Cyt $c$ in a CsA-dependent manner but also induce cellular events that indirectly trigger Cyt $c$ release in a CsA-independent manner. The consensus is that AIF release requires MPT and $\downarrow \Delta \Psi \mathrm{m}$, whereas Cyt $c$ release is not always dependent on those events. Drug-induced $\downarrow \Delta \Psi \mathrm{m}$ could play a role before to initiate and/or after to magnify the release of Cyt $c$. The $\downarrow \Delta \Psi$ m causing matrix remodeling might unfold the cristae and redistribute most of the Cyt $c$ from the closed cristae, where it is sequestered and resistant to release by agents that disturb the OM, to the IMS where it is more susceptible to be released (11). Following $\downarrow \Delta \Psi \mathrm{m}$, matrix remodeling might not induce but simply facilitate the complete recruitment and release of Cyt $c$ (11). Bax activation may be a more plausible candidate for Cyt $c$ release than $\downarrow \Delta \Psi \mathrm{m}$ (17). Following activation of the BH3-only molecules, a bifurcated pathway might ensure the complete release of Cyt $c$ (57). One arm would activate Bax and Bak to initiate the release of some Cyt $c$ across the permeabilized OM in a CsA-insensitive and $\mathrm{Ca}^{2+}$ - and MPT-independent manner, whereas another arm would involve Bax/Bak-independent but CsA-sensitive and $\mathrm{Ca}^{2+}$ - and MPT-dependent events, such as $\downarrow \Delta \Psi \mathrm{m}$ and IM remodeling, required to mobilize and fully release the cristae stores of Cyt $c(57,58)$. As drugs that target isolated mitochondria induce the release of AIF (7), it would be of interest to determine whether PTP-interacting AQs would directly trigger a CsA-inhibitable, $\mathrm{Ca}^{2+}$-sensitive and MPT-dependent release of AIF and a caspase-independent process of nuclear apoptosis (24).

The open-closed transition of the PTP is regulated by matrix and membrane factors (15). The hypothesis that AQs interact with components of the PTP is substantiated by the finding that the ability of these antitumor compounds to mimic the mitochondrial $\downarrow \Delta \Psi \mathrm{m}$, swelling and $\mathrm{Ca}^{2+}$ release caused by known inducers of PTP opening is inhibited by selected PTP blockers. ANT, which regulates the exchange of adenine nucleotides across the IM, is a carrier protein specific for ADP and ATP with two conformational c- and m-states, depending on whether its hydrophilic ligand-binding loop faces the cytoplasm or matrix sides. Proapoptotic drugs and Bcl-2 members which target ANT might induce conformational changes that fix its c-state, block its ability to transport ADP, and induce a CsA-insensitive release of Cyt $c$ by an MPTindependent mechanism in the absence of mitochondrial swelling (59). Whether AQs can inhibit the ANT-mediated transport of ADP in isolated mitochondria remains to be studied. Pretreatments with BA and the natural ANT ligand ADP, which fix ANT conformation in the m-state, all suppress the ability of ANT-interacting drugs to induce Cyt $c$ release by fixing ANT in its c-state (59). Since BA and ADP inhibit AQ-induced mitochondrial $\downarrow \Delta \Psi \mathrm{m}(6)$, swelling and $\mathrm{Ca}^{2+}$ release, such pretreatments might prevent AQs from interacting with ANT to induce conformational changes that trigger MPT and Cyt $c$ and AIF releases. ANT-1 and cyclophilin D overexpression promote MPT and induce apoptosis (60). Normally, ANT-bound cyclophilin D may facilitate a $\mathrm{Ca}^{2+}$ triggered conformational change that promotes ANT opening (61). Since the mitochondrial effects of AQs are CsA-sensitive, the interaction of CsA with cyclophilin D might form a complex that prevents cyclophilin D from binding to the ANT and strongly inhibits MPT $(61,62)$.

Quinones may interact with the quinone-binding site of the PTP to induce conformational changes that alter its $\mathrm{Ca}^{2+}$ binding affinity, making it either less or more sensitive to $\mathrm{Ca}^{2+}$, and define the minimal $\mathrm{Ca}^{2+}$ load required to induce PTP opening (63-66). (OH)d-Ub stimulates, whereas $\mathrm{Ub}_{0}$ and $\mathrm{d}-\mathrm{Ub}$ inhibit, pore opening because they respectively lower or raise the $\mathrm{Ca}^{2+}$ load required to initiate MPT (65). $\mathrm{Ub}_{0}$ may be a stronger PTP blocker than CsA (66). Inactive $\mathrm{Ub}_{5}$ can block both the stimulatory or inhibitory effects of other PTPinteracting quinones, suggesting that all quinones compete for a common binding site (65). The PTP of isolated mitochondria opens in the presence of $100 \mu \mathrm{M} \mathrm{Ca}^{2+}$ but does not in the presence of $20 \mu \mathrm{M} \mathrm{Ca}^{2+}$ or AQs alone. However, AQs induce mitochondrial $\downarrow \Delta \Psi \mathrm{m}$, swelling and $\mathrm{Ca}^{2+}$ release in the presence of $20 \mu \mathrm{M} \mathrm{Ca}^{2+}$, an effect which is inhibited by d-Ub, $\mathrm{Ub}_{0}, \mathrm{Ub}_{5}$ and $\mathrm{Ub}_{10}$, suggesting that AQs might interact with the Ub-quinone-binding site of the PTP to induce conformational changes that make it possible for priming concentrations of $\mathrm{Ca}^{2+}$ to access the $\mathrm{Ca}^{2+}$-binding site regulating its transition 
from the closed to the open state. AQs might interfere with endogenous $\mathrm{Ub}$, which normally binds to PTP and stabilizes it in the closed conformation. In this context, $\mathrm{Ca}^{2+}$ binding and PTP opening can be achieved either by increasing the $\mathrm{Ca}^{2+}$ load or by displacing the inhibitory Ub (65). The closed PTP can exist in 2 quinone-liganted states which confer different conformations resulting in different accessibility to $\mathrm{Ca}^{2+}$. In one liganted state, a small $\mathrm{Ca}^{2+}$ load is sufficient to open the PTP, whereas in the other state, a much higher $\mathrm{Ca}^{2+}$ load is required to access the $\mathrm{Ca}^{2+}$-binding site that opens the PTP (67). Since AQs lower from 100 to $20 \mu \mathrm{M}$ the $\mathrm{Ca}^{2+}$ concentration required to induce mitochondrial $\downarrow \Delta \Psi \mathrm{m}(6)$, swelling and $\mathrm{Ca}^{2+}$ release, the AQ-liganted state might confer a conformation to the pore that enhances its $\mathrm{Ca}^{2+}$ sensitivity.

\section{Acknowledgements}

This study was supported by grants from the National Institutes of Health (National Cancer Institute RO1 CA86842, National Institute on Aging RO1 AG025500 and Center of Biomedical Research Excellence RR15563, with matching funds from the State of Kansas), The National Science Foundation (CHE0555341 and NSF-EPSCoR Planning Grant NSF43529), the American Heart Association (0750115Z), the Howard Hughes Medical Institute (Biological Sciences Education Grant) and Kansas State University (Targeted Excellence 283000 and Terry C. Johnson Center for Basic Cancer Research).

\section{References}

1. Perchellet EM, Magill MJ, Huang X, Dalke DM, Hua DH and Perchellet JP: 1,4-Anthraquinone: an anticancer drug that blocks nucleoside transport, inhibits macromolecule synthesis, induces DNA fragmentation and decreases the growth and viability of L1210 leukemic cells in the same nanomolar range as daunorubicin in vitro. Anticancer Drugs 11: 339-352, 2000.

2. Wu M, Wang B, Perchellet EM, Sperfslage BJ, Stephany HA, Hua DH and Perchellet JP: Synthetic 1,4-anthracenediones, which block nucleoside transport and induce DNA fragmentation, retain their cytotoxic efficacy in daunorubicin-resistant HL-60 cell lines. Anticancer Drugs 12: 807-819, 2001.

3. Perchellet EM, Wang Y, Weber RL, et al: Synthetic 1,4anthracenedione analogs induce cytochrome $c$ release, caspase$9,-3$, and -8 activities, poly(ADP-ribose) polymerase- 1 cleavage and internucleosomal DNA fragmentation in HL-60 cells by a mechanism which involves caspase- 2 activation but not Fas signaling. Biochem Pharmacol 67: 523-537, 2004.

4. Hua DH, Lou K, Havens J, Perchellet EM, Wang Y, Perchellet JP and Iwamoto T: Synthesis and in vitro anti-tumor activity of substituted anthracene-1,4-diones. Tetrahedron 60: 10155-10163, 2004.

5. Hua DH, Lou K, Battina SK, Zhao H, Perchellet EM, Wang Y and Perchellet JP: Syntheses, molecular targets and antitumor activities of novel triptycene bisquinones and 1,4-anthracenedione analogs. Anticancer Agents Med Chem 6: 303-318, 2006.

6. Wang Y, Perchellet EM, Ward MM, Lou K, Hua DH and Perchellet JP: Rapid collapse of mitochondrial transmembrane potential in HL-60 cells and isolated mitochondria treated with antitumor 1,4-anthracenediones. Anticancer Drugs 16: 953-967, 2005.

7. Fulda S, Scaffidi C, Susin SA, Krammer PH, Kroemer G, Peter ME and Debatin KM: Activation of mitochondria and release of mitochondrial apoptogenic factors by betulinic acid. J Biol Chem 273: 33942-33948, 1998.

8. Susin SA, Larochette N, Geuskens M and Kroemer G: Purification of mitochondria for apoptosis assays. Methods Enzymol 322: 205-208, 2000.

9. Blattner JR, He L and Lemasters JJ: Screening assays for the mitochondrial permeability transition using a fluorescence multiwell plate reader. Anal Biochem 295: 220-226, 2001.
10. Custodio JBA, Cardoso CMP and Almeida LM: Thiol protecting agents and antioxidants inhibit the mitochondrial permeability transition promoted by etoposide: implications in the prevention of etoposide-induced apoptosis. Chem Biol Interact 140: 169-184, 2002.

11. Gottlieb E, Armour SM, Harris MH and Thompson CB: Mitochondrial membrane potential regulates matrix configuration and cytochrome $c$ release during apoptosis. Cell Death Differ 10: 709-717, 2003.

12. Zamzami N, Maisse C, Metivier D and Kroemer G: Measurement of membrane permeability and permeability transition of mitochondria. Methods Cell Biol 65: 147-158, 2001.

13. Halestrap AP: The regulation of the matrix volume of mammalian mitochondria in vivo and in vitro and its role in the control of mitochondrial metabolism. Biochim Biophys Acta 973: 355-382, 1989.

14. Henry TR, Solem LE and Wallace KB: Channel-specific induction of the cyclosporine A-sensitive mitochondrial permeability transition by menadione. J Toxicol Environ Health 45: 489-504, 1995.

15. Bernardi P: Mitochondrial transport of cations: channels, exchangers, and permeability transition. Physiol Rev 79: 1127-1155, 1999.

16. Zoratti $M$ and Szabo I: The mitochondrial permeability transition. Biochim Biophys Acta 1241: 139-176, 1995.

17. Ly JD, Grubb DR and Lawen A: The mitochondrial membrane potential $(\Delta \Psi \mathrm{m})$ in apoptosis; an update. Apoptosis 8: 115-128, 2003.

18. Bernardi P, Broekemeier KM and Pfeiffer DR: Recent progress on regulation of the mitochondrial permeability transition pore; a cyclosporin-sensitive pore in the inner mitochondrial membrane. J Bioenerg Biomembr 26: 509-517, 1994.

19. Pervaiz S, Seyed MA, Hirpara JL, Clément M-V and Loh KW: Purified photoproducts of merocyanine 540 trigger cytochrome $c$ release and caspase 8-dependent apoptosis in human leukemia and melanoma cells. Blood 93: 4096-4108, 1999.

20. Gunter KK and Gunter TE: Transport of calcium by mitochondria. J Bioenerg Biomembr 26: 471-485, 1994.

21. Bernardi P and Petronilli V: The permeability transition pore as a mitochondrial calcium release channel: a critical appraisal. J Bioenerg Biomembr 28: 131-138, 1996.

22. Decaudin D, Marzo I, Brenner C and Kroemer G: Mitochondria in chemotherapy-induced apoptosis: a prospective novel target of cancer therapy (Review). Int J Oncol 12: 141-152, 1998.

23. Grad JM, Cepero E and Boise LH: Mitochondria as targets for established and novel anti-cancer agents. Drug Resist Updates 4: 85-91, 2001

24. Joseph B, Marchetti P, Formstecher P, Kroemer G, Lewensohn R and Zhivotovsky B: Mitochondrial dysfunction is an essential step for killing of non-small cell lung carcinomas resistant to conventional treatment. Oncogene 21: 65-77, 2002.

25. Hockenbery DM: A mitochondrial Achilles' heel in cancer? Cancer Cell 2: 1-2, 2002.

26. Solary E, Bettaieb A, Dubrez-Daloz L and Corcos L: Mitochondria as a target for inducing death of malignant hematopoietic cells. Leuk Lymphoma 44: 563-574, 2003.

27. Morisaki T and Katano M: Mitochondria-targeting therapeutic strategies for overcoming chemoresistance and progression of cancer. Curr Med Chem 10: 2517-2521, 2003.

28. Dias N and Bailly C: Drugs targeting mitochondrial functions to control tumor cell growth. Biochem Pharmacol 70: 1-12, 2005.

29. Robertson JD, Gogvadze V, Zhivotovsky B and Orrenius S Distinct pathways for stimulation of cytochrome $c$ release. J Biol Chem 275: 32438-32443, 2000.

30. Huigsloot M, Tijdens IB, Mulder GJ and van de Water B Differential regulation of doxorubicin-induced mitochondrial dysfunction and apoptosis by Bcl-2 in mammary adenocarcinoma (MTLn3) cells. J Biol Chem 277: 35869-35879, 2002.

31. Rebbaa A, Chou PM, Emran M and Mirkin BL: Doxorubicininduced apoptosis in caspase-8-deficient neuroblastoma cells is mediated through direct action on mitochondria. Cancer Chemother Pharmacol 48: 423-428, 2001.

32. Tong X, Lin S, Fujii M and Hou D-X: Echinocystic acid induces apoptosis in HL-60 cells through mitochondria-mediated death pathway. Cancer Lett 212: 21-32, 2004.

33. Zhang S, Ong C-N and Shen H-M: Involvement of proapoptotic Bcl-2 family members in parthenolide-induced mitochondrial dysfunction and apoptosis. Cancer Lett 211: 175-188, 2004. 
34. Kim JS, Lee JM, Chwae Y-J, et al: Cisplatin-induced apoptosis in Hep3B cells: mitochondria-dependent and -independent pathways. Biochem Pharmacol 67: 1459-1468, 2004.

35. Ahn HJ, Kim YS, Kim J-U, Han SM, Shin JW and Yang HO: Mechanism of taxol-induced apoptosis in human SKOV3 ovarian carcinoma cells. J Cell Biochem 91: 1043-1052, 2004.

36. Shibata M-A, Ito Y, Morimoto J and Otsuki Y: Lovastatin inhibits tumor growth and lung metastasis in mouse mammary carcinoma model: a p53-independent mitochondrial-mediated apoptotic mechanism. Carcinogenesis 25: 1887-1898, 2004.

37. Hsu M-J, Chao Y, Chang Y-H, et al: Cell apoptosis induced by a synthetic carbazole compound LCY-2-CHO is mediated through activation of caspase and mitochondrial pathways. Biochem Pharmacol 70: 102-112,2005.

38. Ko CH, Shen S-C, Hsu C-S and Chen Y-C: Mitochondrialdependent, reactive oxygen species-independent apoptosis by myricetin: roles of protein kinase $\mathrm{C}$, cytochrome $c$, and caspases. Biochem Pharmacol 69: 913-927, 2005.

39. Sen N, Das BB, Ganguly A, et al: Camptothecin induced mitochondrial dysfunction leading to programmed cell death in unicellular hemoflagellate Leishmania donovani. Cell Death Differ 11: 924-936, 2004.

40. Piret J-P, Arnould T, Fuks B, Chatelain P, Remacle J and Michiels C: Mitochondria permeability transition-dependent tert-butyl hydroperoxide-induced apoptosis in hepatoma HepG2 cells. Biochem Pharmacol 67: 611-620, 2004.

41. Schempp CM, Kirkin V, Simon-Haarhaus B, et al: Inhibition of tumour cell growth by hyperforin, a novel anticancer drug from St. John's wort that acts by induction of apoptosis. Oncogene 21: $1242-1250,2002$

42. Marchetti P, Zamzami N, Joseph B, et al: The novel retinoid 6[3-(1-adamantyl)-4-hydroxyphenyl]-2-naphtalene carboxylic acid can trigger apoptosis through a mitochondrial pathway independent of the nucleus. Cancer Res 59: 6257-6266, 1999.

43. Ricci J-E, Waterhouse N and Green DR: Mitochondrial functions during cell death, a complex (I-V) dilemma. Cell Death Differ 10: 488-492, 2003.

44. Brdiczka D, Beutner G, Rück A, Dolder M and Wallimann T: The molecular structure of mitochondrial contact sites. Their role in regulation of energy metabolism and permeability transition. BioFactors 8: 235-242, 1998.

45. Donovan M and Cotter TG: Control of mitochondrial integrity by Bcl-2 family members and caspase-independent cell death. Biochim Biophys Acta 1644: 133-147, 2004.

46. Shimizu S, Narita M and Tsujimoto Y: Bcl-2 family proteins regulate the release of apoptogenic cytochrome $c$ by the mitochondrial channel VDAC. Nature 399: 483-487, 1999.

47. Zamzami N and Kroemer G: The mitochondrion in apoptosis: how Pandora's box opens. Nat Rev Mol Cell Biol 2: 67-71, 2001.

48. Marzo I, Brenner C, Zamzami N, et al: Bax and adenine nucleotide translocator cooperate in the mitochondrial control of apoptosis. Science 281: 2027-2031, 1998.

49. Wei MC, Zong WX, Cheng EH, et al: Proapoptotic Bax and Bak: a requisite gateway to mitochondrial dysfunction and death. Science 292: 727-730, 2001

50. Gogvadze V, Robertson JD, Enoksson M, Zhivotovsky B and Orrenius S: Mitochondrial cytochrome $c$ release may occur by volume-dependent mechanisms not involving permeability transition. Biochem J 378: 213-217, 2004.

51. Vyssokikh M, Zorova L, Zorov D, Heimlich G, Jürgensmeier J, Schreiner D and Brdiczka D: The intramitochondrial cytochrome $c$ distribution varies correlated to the formation of a complex between VDAC and the adenine nucleotide translocase: this affects Bax-dependent cytochrome $c$ release. Biochim Biophys Acta 1644: 27-36, 2004.
52. Kim TH, Zhao Y, Barber MJ, Kuharsky DK and Yin XM Bid-induced cytochrome $c$ release is mediated by a pathway independent of mitochondrial permeability transition pore and Bax. J Biol Chem 275: 39474-39481, 2000.

53. Shimizu S, Matsuoka Y, Shinohara Y, Yoneda Y and Tsujimoto Y: Essential role of voltage-dependent anion channel in various forms of apoptosis in mammalian cells. J Cell Biol 152: 237-250, 2001

54. Bossy-Wetzel E, Newmeyer DD and Green DR: Mitochondrial cytochrome $c$ release in apoptosis occurs upstream of DEVD-specific caspase activation and independently of mitochondrial transmembrane depolarization. EMBO J 17: 37-49, 1998

55. Zhuang J, Dinsdale D and Cohen GM: Apoptosis, in human monocytic THP.1 cells, results in the release of cytochrome $c$ from mitochondria prior to their ultracondensation, formation of outer membrane discontinuities and reduction in inner membrane potential. Cell Death Differ 5: 953-962, 1998

56. Hearps AC, Burrows J, Connor CE, Woods GM, Lowenthal RM and Ragg SJ: Mitochondrial cytochrome $c$ release precedes transmembrane depolarization and caspase- 3 activation during ceramide-induced apoptosis of Jurkat T cells. Apoptosis 7: 387-394, 2002.

57. Scorrano L and Korsmeyer SJ: Mechanisms of cytochrome $c$ release by proapoptotic $\mathrm{Bcl}-2$ family members. Biochem Biophys Res Commun 304: 437-444, 2003.

58. Gogvadze V, Robertson JD, Zhivotovsky B and Orrenius S: Cytochrome $c$ release occurs via $\mathrm{Ca}^{2+}$-dependent and $\mathrm{Ca}^{2+}$ independent mechanisms that are regulated by Bax. J Biol Chem 276: 19066-19071, 2001.

59. Machida $\mathrm{K}$, Hayashi $\mathrm{Y}$ and Osada $\mathrm{H}$ : A novel adenine nucleotide translocase inhibitor, MT-21, induces cytochrome $c$ release by a mitochondrial permeability transition-independent mechanism. J Biol Chem 277: 31243-31248, 2002.

60. Bauer MK, Schubert A, Rocks O and Grimm S: Adenine nucleotide translocase-1, a component of the permeability transition pore, can dominantly induce apoptosis. J Cell Biol 147: 1493-1502, 1999.

61. Halestrap A: A pore way to die. Nature 434: 578-579, 2005.

62. Zoratti M, Szabò I and De Marchi U: Mitochondrial permeability transitions: how many doors to the house? Biochim Biophys Acta 1706: 40-52, 2005 .

63. Walter L, Miyoshi H, Leverve X, Bernardi P and Fontaine E: Regulation of the mitochondrial permeability transition pore by ubiquinone analogs. A progress report. Free Radic Res 36: 405-412, 2002.

64. Henry TR and Wallace KB: Differential mechanisms of induction of the mitochondrial permeability transition by quinones of varying chemical reactivities. Toxicol Appl Pharmacol 134: 195-203, 1995.

65. Fontaine E, Ichas F and Bernardi P: A ubiquinone-binding site regulates the mitochondrial permeability transition pore. J Biol Chem 273: 25734-25740, 1998.

66. Kristián T, Gertsch J, Bates TE and Siesjö BK: Characteristics of the calcium-triggered mitochondrial permeability transition in nonsynaptic brain mitochondria: effect of cyclosporin A and ubiquinone 0. J Neurochem 74: 1999-2009, 2000.

67. Ichas F and Mazat JP: From calcium signaling to cell death: two conformations for the mitochondrial permeability transition pore. Switching from low- to high-conductance state. Biochim Biophys Acta 1366: 33-50, 1998. 